\title{
Massa Intracardíaca em Provável Caso de Granulomatose de Wegener
}

\author{
Thelma L. Skare, Dimitri M. Zappi \\ Curitiba, PR
}

\begin{abstract}
A granulomatose de Wegener, doença conhecida há aproximadamente 65 anos, continua sendo um dilema para a classe médica, talvez pelo seu polimorfismo clínico, talvez pela carência de métodos diagnósticos. Seu diagnóstico laboratorial repousa no binômio: dosagem do anticorpo anti-neutrófilo em sua fração citoplasmática (ANCA-c) e na obtenção de material para análise anatomopatológica. Descrevemos aqui, o caso de um paciente, em cuja evolução clínica pôde ser observada todo aspecto proteiforme desta doença, chamando atenção para o envolvimento cardíaco. Este último considerado por muitos como pouco usual, manifestou-se clinicamente sob a forma de miocardite, pericardite e de uma massa intracardíaca.
\end{abstract}

\section{Wegener's Granulomatosis in a Patient with Intracardiac Mass}

Although Wegener's granulomatosis is known for almost 65 years, the disease is still a dilemma for physicians. This is probably due to its different clinical presentations or to the lack of diagnostic methods. The laboratorial diagnosis is supported on the presence of antineutrophil cytoplasmic antibodies (ANCA-c) and on histological analysis of tissues from affected organs. This paper describes a case report of a patient whose clinical history presented all protean aspects of the disease, including cardiac involvement such as myocarditis, pericarditis and, surprisingly, intracardiac mass.

Arq Bras Cardiol, volume 71 (n 4), 609-611, 1998

A granulomatose de Wegener (GW), entidade descrita originalmente por Klingerem $1931 \mathrm{e}$, posteriormente, melhor caracterizada por Wegener em 1936, é classicamente uma doença de adultos, com um pico de incidência na $4^{\mathrm{a}} \mathrm{e} 5^{\mathrm{a}}$ décadas, que se apresenta tipicamente como uma síndrome pulmonar-renal. Relatos recentes ${ }^{1-3}$ têm demonstrado que o acometimento de indivíduos numa faixa etária mais jovemé bem maior do que previamente suposto. Isto pode ser atribuído a um melhor conhecimento dos diferentes aspectos clínicos desta doença, por parte dos médicos atendentes, e, também, a uma melhoria nas condições de investigação laboratorial, principalmente através do anticorpo antineutrófilo em sua fração citoplasmática (ANCA-c), permitindo que o diagnóstico seja feito de forma mais precoce.

Apesar de todos estes avanços, a GW, devido ao seu polimorfismo clínico, ainda é um problema diagnóstico.

Faculdade Evangélica de Medicina do Paraná (FEMPAR) - Curitiba Correspondência: Dimitri Mikaelis Zappi - Rua Des Otávio do Amaral, 448/51 80730-400 - Curitiba, PR

Recebido para publicação em 9/5/98

Aceito em 15/7/98
Descrevemos, aqui, um caso, em paciente jovem, em cuja evolução pôde ser apreciado todo o aspecto proteiforme da doença, inclusive a apresentação de um aspecto bastante incomum, o de uma massa intracardíaca.

\section{Relato do Caso}

Paciente de 25 anos, masculino, hígido até dois meses atrás, quando, após drenagem de abcesso periodontal, iniciou um quadro de tosse não produtiva, coriza, hiperemia conjuntival, astenia e anorexia. Foi avaliado ambulatorialmente, sendo tratado com sintomáticos sem melhora. Passou a observar aparecimento de sudorese vespertina associada a febre e perda de $6 \mathrm{~kg}$ neste período, quando então, procurou o Hospital Universitário Evangélico de Curitiba. Negava uso de drogas, tabagismo e contato com possíveis portadores de tuberculose. Na avaliação inicial, estava emagrecido, febril $\left(38,3^{\circ} \mathrm{C}\right)$ e com diminuição difusa no murmúrio vesicular. Uma radiografia de tórax inicial revelou condensações focais para hilares e lesões pulmonares cavitadas em lobo superior esquerdo. $O$ paciente foi admitido com diagnóstico presuntivo de vários abcessos pulmonares, secundários à aspiração de microrganismo de infecção perio- 
dontal e tratado, inicialmente, com penicilina cristalina. Exames complementares iniciais mostraram uma anemia normocrônica e normocítica com volume globular(VG) de 32,7\%, 13.300 leucócitos com $10 \%$ de bastões, as plaquetas eram $645.000 / \mathrm{mm}^{3}$. Uréia, creatinina, sódio, potássio, glicemia e parcial de urina eram normais. Após cinco dias de tratamento, como o estado geral do paciente permanecia o mesmo e a febre não cedia, foi modificado o esquema antibiótico para metronidazol, ceftriaxone e vancomicina. Na evolução, foi solicitado nova radiografia de tórax, que evidenciou o aparecimento de lesões cavitadas também em lobo médioà direita. Um hemograma subseqüente mostrou queda do VG para 27\% e piora da leucocitose, agora de 19.900/ $\mathrm{mm}^{3}$. Uma vez que não se conseguia isolar qualquer germe nas hemoculturas e exames de escarro (bacterioscopia, pesquisa de Baar, cultura), foi realizada uma fibrobroncoscopia com coleta de lavado brônquico, a qual demonstrou hiperemia de mucosa brônquica sem outras alterações anatômicas; o lavado tinha 100 hemácias $/ \mathrm{mm}^{3}$, nenhum leucócito e foi negativo para fungos e Baar. Sorologia para HIV e PPD foram negativas. Como o estado clínico do paciente deteriorava-se, apesar da terapêutica adotada, prosseguiu-se investigação através de uma tomografia de tórax que mostrou derrame pleural bilateral e lesões cavitadas em ambos pulmões. Foi solicitado então uma biópsia pleural que demonstrou processo inflamatório inespecífico. Após 13 dias de mudança de esquema antimicrobiano, como a febre persistia e não existia comprovação laboratorial de algum germe específico, foi adicionadoempiricamente rifampicina, isoniazida e pirazinamida. A seguir, o paciente passou a referir dor torácicainespecífica e surgiu, ao exame, um sopro sistólico em borda esternal inferior esquerda, sendo então solicitado um eletrocardiograma e um ecocardiograma. O primeiro mostrou complexos de baixa voltagem com onda T apiculada, área eletricamente inativa em parede lateral alta e isquemia subendocárdica em parede lateral. O ecocardiograma revelou aumento global de câmaras, com massa em ventrículo direito e esquerdo(VE), hipocinesia difusa de VE de grau discreto (fração de ejeção de 68\%), derrame pericárdico discreto (fig. 1). Novos exames laboratoriais demonstraram nova queda de VG, agora para $23 \%$ e elevação importante de creatinina para $11,4 \mathrm{mg} / \mathrm{dL}$, com uréia de $212 \mathrm{mg} / \mathrm{dL}$. A VHS era de $112 \mathrm{~mm} / 1^{\mathrm{a}}$ hora; sódio de $134 \mathrm{mEq} / \mathrm{L}$, potássio de $7,1 \mathrm{mEq} / \mathrm{L}$. A gasometria demonstrava $\mathrm{pH}$ de 7,27, $\mathrm{pCO} 2$ de $31 \mathrm{mmoL} / \mathrm{L}, \mathrm{pO} 2 \mathrm{de}$ $71 \mathrm{mmoL} / \mathrm{LeHCO} 3 \mathrm{de} 13,7 \mathrm{mEq} / \mathrm{L}$. Oparcial de urina apresentava proteinúria de $1,18 \mathrm{~g} / \mathrm{L}$. Uma nova radiografia de tórax mantinha mesmo padrão pulmonar anterior, porém agora com aumento de área cardíaca. A partir deste momento foi iniciada investigação para GW através de radiografia de seios paranasais e dosagem de ANCA-c que mostraram respectivamente, hipotransparência de seio maxilar direito e ANCA-c reagente na titulação de 1/40. Foi instituída pulsoterapia com metilprednisolona e diálise peritoneal. Uma biópsia renal havia sido programada, após a qual se iniciaria ciclofosfamida. Porém, o paciente evoluiu com dispnéia súbita associada a hemoptise franca, seguida de parada cardiorrespiratória, sendo entubado e reanimado sem sucesso. A necropsia não foi autorizada pela família.

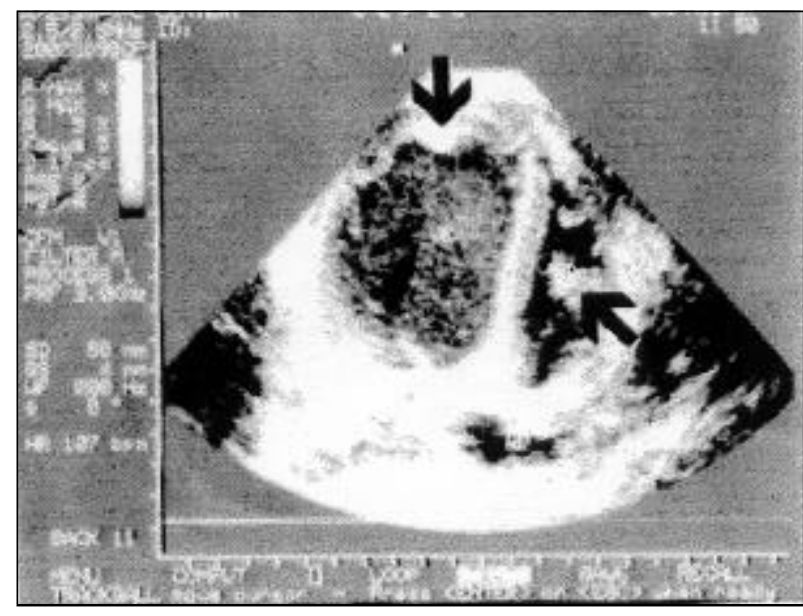

Fig. 1 - Imagem ecocardiográfica demonstrando a presença de massas intracardíacas volumosas (setas), aumento global de câmaras com espessamento e derrame pericárdico discreto.

\section{Discussão}

A GW é uma vasculite necrotizante que, tipicamente, afeta trato respiratório superior, inferior e rins. A confirmação laboratorial de seu diagnóstico repousa no binômio de detecção do ANCA-c e estudo anatomopatológico de material biopsiado.

Rao e $\mathrm{Col}^{4}$, em um estudo de metanálise sobre a validade do ANCA-c no diagnóstico de granulomatose Wegener, envolvendo outros 15 estudos publicados, encontraram que este teste demonstra uma sensibilidade de $66 \%$ e uma especificidade de $98 \%$. Nosso paciente tinha um ANCA-c positivo num título de $1 / 40$.

O outro pilar diagnóstico, que é a confirmação histológica de uma vasculite granulomatosa com abundante necrose extra vascular, deve ser obtida preferencialmente de tecidos de vias áreas superiores ou inferiores comprometidos, os quais fornecem uma maior positividade que o tecido renal. Freqüentemente é necessário que, para uma análise anatomopatológica adequada, se forneça uma porção generosa de tecido. Isto talvez explique a baixa positividade deste diagnóstico em biópsias transbrônquicas.

Nosso paciente não tinha condições clínicas para se submeter a uma biópsia pulmonar a céu aberto. Como a biópsia pleural não logrou demonstrar o diagnóstico, optou-se, então pela biópsia renal, a qual não chegou a ser realizada devido ao óbito. Deste modo, apesar de não ter sido possível confirmação histológica, o diagnóstico de GW tornou-se bastante provável, baseado na evolução clínica do paciente, que se apresentou típica no decorrer do internamento e pela presença do ANCA-c em títulos elevados.

No entanto, em nosso paciente, o que mais chamou a atenção, pelo seu aspecto pouco usual, foi o envolvimento cardíaco, principalmente o aparecimento de massa intracardíaca detectada à ecocardiografia.

$\mathrm{O}$ acometimento cardíaco do portador de GW tem sido considerado raro, o que pode não refletir a realidade. Goodfield e $\mathrm{col}^{2}$ analisaram, retrospectivamente, diversos 
trabalhos, encontrando envolvimento cardíaco em quatro a $44 \%$ dos pacientes descritos. Este envolvimento pode ser global ou se manifestar isoladamente como miocardite, endocardite (valvulite, massa intracadíaca), vasculite (angina, infarto do miocárdio (IM), aortite), arritmia e/ou pericardite. Forstot e $\mathrm{col}^{5}$ que estudaram pacientes com GW com manifestações cardíacas, encontraram que, aproximadamente $50 \%$ destes tinham pericardite, $50 \%$ vasculite coronária, $25 \%$ miocardite, $21 \%$ valvulite ou endocardite, com arritmia $17 \%$ e $11 \%$ com IM. Em nosso paciente os achado ecocardiográficos sugerem além da massa intracardíaca, a ocorrência de miocardite, e pericardite. A ocorrência de massa intracardíaca parece ser particularmente rara, apenas Kosovsky e $\mathrm{col}^{6}{ }^{6}$ descreveram caso similar, também em um paciente jovem, que desenvolveu extensa área de vasculite, envolvendo endocárdio que se exteriorizou-se como uma massa intracardíaca, detectada fortuitamente à ressonância magnética. Além desse mecanismo descrito por Kosovsky e $\operatorname{col}^{6}$ para a formação da massa, não se pode esquecer a possibilidade de que a mesma possa re- sultar de um trombo mural de grandes proporções. É fácil compreender que a miocardite por si só predisponha a um ambiente trombogênico. No trabalho de Fauci e $\mathrm{col}^{7}$, pequenos trombos murais foram encontrados em endocárdio de pacientes com Wegener. A não autorização da necropsia, prejudicou neste caso, a análise histológica do processo visualizado à ecocardiografia.

Desta maneira, nos casos com suspeita de GW, devese ter alto índice de suspeição quanto à possibilidade de envolvimento cardíaco, valorizando com maior rigor nesses pacientes, qualquer mudança nos parâmetros hemodinâmicos e queixas relativas a este sistema. Os critérios para realização de exames complementares, com vistas a investigação do sistema cardiovascular, devem ser menos rigorosos e realizados com maior frequiência.

Pela sua apresentação clínica dramática, este caso ilustra que, juntamente com os rins e pulmões, o coração pode determinar o prognóstico nos pacientes com $\mathrm{GW}$, e ainda, em pacientes com massa intracardíaca sem etiologia evidente, a possibilidade de GW faça parte do diagnóstico diferencial.

\section{Referências}

1. Grant SCD, Levy RD, Venning MC, Ward C, Brooks NH - Wegener's granulomatosis and the heart. Br Heart J 1994; 71: 82-6.

2. Goodfield NER, Bhandari S, Plant WD, Morfey-Davies A, Sutherland GR Cardiac involvement in Wegener's granulomatosis. Br Heart J 1995; 73: 110-15.

3. Halstead LA, Karmody CS, Wolff SM - Presentation of Wegener's granulomatosis in young patients. Otolaryngol Head Neck Surg 1986; 94: 368-71.

4. Rao JK, Weinberg M, Oddone EZ, Allen NB, Landsman P, Feussner JR - The role of antineutrophil cytoplasmic antibody (c-ANCA) testing in the diagnosis of Wegener granulomatosis. Ann Intern Med 1995; 123: 925-32.
5. Forstot JZ, Overlie PA, Neufeld GK, Harmon CE, Forstot SL - Cardiac complications of Wegener granulomatosis: a case report of complete heart block and review of literature. Semin Atrhritis Rheum 1980; 10: 148-54

6. Kosovsky PA, Ehlers KH, Rafal RB, Williams WM, O'Loughlin JE, Markisz JA - MR imaging of cardiac mass in Wegener granulomtosis. J Comput Assist Tomogr 1991; 15: 1028-30.

7. Fauci AS, Wolff SM - Wegener's granulomatosis: studies in eighteen patients and a review of the literature. Medicine 1973; 52: 536-61. 